\title{
AUTORITARISMO, FRAGILIDADES E PARADOXOS NAS PARTICIPAÇÕES SOCIAIS BRASILEIRAS
}

Wagner Vinicius de Oliveira*

\begin{tabular}{l|l}
\hline RECEBIDO EM: & 17.4 .2020 \\
\hline APROVADO EM: & $\mathbf{2 2 . 6 . 2 0 2 0}$ \\
\hline
\end{tabular}

* Doutorando em Direito da Universidade Federal do Rio de Janeiro (UFRJ), bolsista pela Coordenação de Aperfeiçoamento de Pessoal de Nível Superior (CAPES), mestre em Direito pela Universidade Federal de Uberlândia (UFU) e bacharel em Direito pela Pontifícia Universidade Católica de Minas Gerais (PUCMinas). Advogado. E-mail: oliveirawagnervinicius@gmail.com 
- RESUMo: Objetiva-se compreender algumas fragilidades e paradoxos enfrentados pelas participações sociais na experiência brasileira com vistas a identificar e explicar o persistente fenômeno autoritário. Como hipótese, sustenta-se que o autoritarismo assume diversas nuances e funções nas práticas institucionais e sociais brasileiras, especificamente, o "autoritarismo instrumental” compromete as ideias de constituição e de constitucionalismo. Busca-se testar essas ideias por meio da estratégia metodológica indutiva e do levantamento teórico-bibliográfico. Para tanto, revisitam-se os pensamentos políticos consagrados e as categorias do "autoritarismo instrumental" e do "povo-massa” para balancear as persistências autoritárias e o movimento na direção contrária (cultura democrática). Os resultados autorizam afirmar que as peculiaridades e as dificuldades enfrentadas tornam a experiência brasileira singular e a intensificação das práticas democráticas após a promulgação da Constituição da República de 1988. Por fim, conclui-se que, apesar dos avanços, tanto a democracia quanto as participações sociais ainda não se incorporaram completamente nas práticas institucionais brasileiras.

- PALAVRAS-ChAVE: autoritarismo instrumental; cultura democrática; participação social.

\section{AUTHORITARIANISM, FRAGILITIES AND PARADOXES} IN BRAZILIAN SOCIAL PARTICIPATIONS

- ABstRAct: The objective is to understand some weaknesses and paradoxes faced by social participation in the Brazilian experience in order to identify and explain the persistent authoritarian phenomenon. As hypothesis, sustains itself that the authoritarianism assumes several nuances and functions in Brazilian institutional and social practices, specifically, the "instrumental authoritarianism" undermines the ideas of constitution and of constitutionalism. To test these ideas, used the inductive methodological strategy and the theoretical-bibliographic survey. To this end, revisits the political thoughts enshrined the categories of "instrumental authoritarianism" and of "mass people" to balance the authoritarian persistence and the movement in the opposite direction (democratic culture). The results authorize to affirm that the peculiarities and the difficulties faced make the 
Brazilian experience unique and, specifically, the intensification of democratic practices after the promulgation of the 1988 Constitution. Finally, in conclusion, despite the advances, both democracy and social participation have not been fully incorporated in the Brazilian institutional practices.

- KEYwords: instrumental authoritarianism; democratic culture; social participation.

\section{Introdução}

Durante o percurso histórico das modernas civilizações ocidentais, ou melhor, daquilo que atualmente se costuma nomear de ocidental (BERMAN, 2006, p. 12), a figura do Estado-força não é peculiar nem assintomática. Ao contrário, em maior ou menor grau, a violência sempre compôs os cenários sociais. Este artigo se dedica a colocar em questão parcela desse entendimento, traduzido no autoritarismo político, pois, na atualidade, pensar as relações de poder é cruzar as fronteiras das relações estabelecidas entre as dominadoras e os dominadores, por um lado, e as dominadas e os dominados, por outro.

Entre outras situações, provoca a paradoxal condição localizada entre o desejo de liberdade e, ao mesmo tempo, o pavor por ela provocada. Para cada receio, real ou fictício, surgem novas tentativas de respostas. $\mathrm{O}$ autoritarismo, em suas variadas correntes e explicações, promete, sem, contudo, efetivar a segurança e o pertencimento coletivo de todas e todos. Nesse cenário, exclusões e buscas por "um messias político, por um salvador da pátria” (CARVALHO, 2002, p. 221) são quase sempre forjadas por critérios arbitrários, tais como a nacionalidade, o gênero, o prestígio social e econômico, entre outros, acompanhados de uma generosa dose de truculência.

Avanços e retrocessos são perpetrados em nome da manutenção ou ampliação das liberdades. Resta identificar os interesses aos quais buscam atender ou ainda as destinatárias e os destinatários finais dessas "liberdades"; geralmente, essas respostas não são apresentadas. Em meio a espaços cada vez mais reduzidos para a liberdade humana, surgem novas configurações para antigos problemas; o príncipe hoje se tornou eletrônico (IANNI, 2003) da mesma maneira que o panóptico tornou-se digital (HAN, 2018). Por outros caminhos, a atualidade do tempo presente esforçou-se para superar a distopia desenhada por Orwell (2019). 
O poder exercido por instituições estatais e sociais não comporta mais ser explicado por intermédio das clássicas categorias ou dos pensamentos políticos consagrados pela Europa continental nos idos dos séculos XVIII e XIX. Essa complexa dinâmica institucional e social reduziu bastante os campos de atuação para uma servidão voluntária (LA BOÉTIE, 1976), embora, em certo sentido, permaneça parcialmente válida para explicar alguns fenômenos. Porém, cada experiência possui singularidades que comprometem a validade de ideias universais e atemporais.

Foi preciso “olhar pelo retrovisor” para enxergar os pensamentos políticos clássicos. Num exercício retrospectivo, trata-se de compreender as experiências hegemônicas apenas como uma reflexão elaborada por um intérprete de seu tempo, as quais, mesmo com o decurso do tempo, permanecem atuais, permitem realizar adaptações ou reinterpretações daqueles pensamentos e, sob suas lentes, possibilitam entender a realidade examinada (BOBBIO, 2000, p. 130-131). Contudo, carregam consigo o germe de uma suposta unidade reveladora de traços fundamentais sobre as ideias concebidas acerca do povo e das instituições políticas (estatais).

A pesquisa desenvolvida assume como vetor a passagem por algumas das clássicas reflexões da filosofia política para repensar as possibilidades de participação social nas decisões fundamentais do Estado brasileiro contemporâneo. O objeto da investigação, sob o pano de fundo do autoritarismo, consiste na insuficiência da participação política materializada pelo voto individual, secreto, periódico e virtualmente universal. Trata-se, portanto, de uma investigação motivada pelo questionamento sobre as permanências e as possíveis rupturas com uma tradição estatal e social de pouca permeabilidade aos ditames democráticos nas práticas institucionais brasileiras.

Se, por um lado, existe um conjunto de práticas atravessadas pelo autoritarismo, alinhado ao surgimento do Estado moderno; por outro lado, há uma crença infundada de que as participações sociais, por si sós, eliminarão de uma vez por todas a autocracia travestida de democracia formal. Ledo engano. Caso as participações sociais não sejam acompanhadas de ideias democráticas e republicanas, poderão fazer parte do problema, e não da solução.

O movimento na direção contrária, chamado de cultura democrática brasileira, será a hipótese investigada teoricamente. Para tanto, lança-se mão da estratégia metodológica indutiva e do levantamento teórico-bibliográfico como ferramentas para perseguir esse objetivo. Busca-se fundamentar o ponto de vista de que a democracia é, antes de tudo, uma ambientação cultural, um substantivo abstrato que precisa ser 
adjetivado e transformado em ação, mas sem se confundir com a oclocracia, isto é, com o governo das multidões.

Estruturas teóricas e institucionais capazes de assegurar em um só tempo igualdade e liberdade, certamente, envolvem alguma noção ligada à ideia do "bom filho da civilização moderna” (ADORNO; HORKHEIMER, 1985, p. 14). Não há balizas seguras para realizar a passagem do autoritarismo incrustrado nos corpos e nas práticas sociais para a completa inclusão do "povo" nas decisões políticas fundamentais e alcançar patamares democráticos nunca antes registrados na história das civilizações ocidentais modernas.

Aliás, historicamente o substantivo povo atua como categoria performativa com pretensão legitimatória do exercício do poder por outrem em seu nome. Uma abstração idealizada, um sujeito coletivo que se apresenta mais como uma figura de linguagem no léxico da filosofia política e do direito constitucional do que uma instância decisória concreta. Sem muitos esforços, é possível identificar que as teorias sociais brasileiras encampam o reforço do “autoritarismo instrumental”(VIANNA, 1999, 2005) e do “povo-massa” (VIANNA, 1999).

Este artigo busca discutir o tema do autoritarismo mobilizando as reflexões contidas na obra Instituições políticas brasileiras (VIANNA, 1999), em virtude de sua relevância para revisitar os pensamentos do autor sobre o tema. Igualmente, articulará outras perspectivas (VIANNA, 1939, 2004, 2005) que colaboram para desenvolver as reflexões, sem necessariamente concordar com suas conclusões; no final das contas, aquilo que se pretende é dialogar com seus diagnósticos.

Esse tipo de análise encontra justificativa ao considerar que momentos de instabilidade econômica, política e social forjam espaços propícios para a "reestruturação geral da sociedade em direção a uma sociedade menos livre e menos igualitária” (GOMES, 2020, p. 4, no prelo). Isso, contudo, não permite afirmar a completa aptidão para extrair ou inferir todas as consequências ou desdobramentos possíveis e assim fornecer uma explicação peremptória para o fenômeno focalizado.

No esforço de construir uma resposta provisória à situação problema examinada, desenvolvem-se três argumentos distintos, quais sejam: primeiro, toma-se, como ponto de partida, a necessidade e, ao mesmo tempo, a insuficiência do contato com os estudos clássicos da filosofia política. Mesmo porque uma autora, um autor ou uma obra somente receberão esse adjetivo se preencherem determinados requisitos - en passant, um tanto quanto contingentes -, isto é, decorrem da convenção 
adotada por um núcleo específico de parcela da sociedade que possui o monopólio do saber-poder.

Foi preciso atravessar os horizontes históricos das linhagens e dos pensamentos políticos de vanguarda para compreender, além das características usualmente trabalhadas, algumas das singularidades da democracia brasileira. Não se cogita a mera repetição como método adequado para alcançar uma explicação satisfatória para a experiência brasileira. Entretanto, não se permite ignorar os trabalhos pioneiros nessa temática. Assim, a investigação também percorrerá outros dois caminhos.

Por meio do manejo das categorias do "autoritarismo instrumental” e das peculiaridades da conformação do Estado nacional brasileiro, pretende-se correlacioná-las com o surgimento do "povo-massa”, na passagem do período imperial para o republicano brasileiro, na formação das instituições políticas, majoritariamente demarcado pela desqualificação do povo e pelas fragilidades institucionais, responsáveis por forjarem a ideia de inaptidão social; logo, as elites ou os clãs assumem o protagonismo na política nacional e fornecem traços marcantes e inseparáveis da historiografia oficial brasileira.

Como linha argumentativa final, busca-se estabelecer reflexões acerca da possibilidade de diagnosticar os elementos que confirmem (ou não) as persistências do caráter autoritário ou, de outra sorte, apontem para a formação de uma “cultura democrática”, ainda que incipiente nas práticas brasileiras. Mesmo ciente de que "O problema do autoritarismo e da democracia não pode ser entendido como um simples resultante de processos sociais gerais” (SCHWARTZMAN, 2007, p. 244), procura-se, entre o político e o jurídico, encontrar espaços para as participações sociais.

Os resultados aportados autorizam duas formulações finais: a primeira, diz respeito às peculiaridades e às dificuldades enfrentadas pela democracia brasileira que a tornam uma experiência singular; a segunda, especialmente após a promulgação da Constituição da República de 1988, que as práticas democráticas foram intensificadas, mas ainda são insuficientes para fazer frente ao fenômeno focalizado.

Entre fragilidades históricas e desafios recentes, alguns valores se desdobram nas participações sociais como expectativa para reduzir os espaços de atuação do autoritarismo político, sem, contudo, incidir na expectativa da dissolução do paradoxo representado pela democracia brasileira. Enfim, a situação observada consiste em demarcar uma distinção do fenômeno do autoritarismo político à luz da ordem constitucional de 1988. 


\section{Revisitar os clássicos do pensamento político é preciso?}

Na tarefa de compreender a democracia brasileira, foi preciso retornar e revisitar os pensamentos clássicos, conforme definição apresentada na parte introdutória deste artigo. Isso, no entanto, não responde por completo à indagação contida nesse primeiro subtítulo. Existe uma ironia que reclama explicações adicionais para equacionar aquilo que há de variante e o que é constante na história do político.

Há tempos se sabe que o sentido atribuído à frase do poeta português Fernando Pessoa ao afirmar que "navegar é preciso, viver não" destoa do entendimento usual. Com efeito, não pretende significar a ponderação entre os valores navegar e viver que estão colocados em contraposição, isto é, a imprescindibilidade ou a necessidade de navegar em detrimento da vida. Ao contrário, pretende designar a inexistência de mapas, caminhos ou métodos seguros para executar as tarefas ligadas ao humano. Exemplo disso seria a própria vida humana que passa a ser compreendida como contraditória e imprecisa por definição.

Noutras palavras, a exatidão ou a precisão, pelo menos quanto ao local de partida e ao local de chegada pretendido, é atribuível ao ato de viajar, não ao de viver. De outro modo, remonta também à tradição portuguesa das navegações colonizadoras. Observadas as proporções e os limites, considerações aproximadas são replicadas quanto aos pensamentos políticos e filosóficos entendidos como clássicos no lado ocidental do mundo.

Significa compreender que a explicação dos fenômenos institucionais e sociais brasileiros realizada exclusivamente pelas lentes dos pensamentos europeus, geralmente produzidos no século XIX, torna as análises imprecisas. Com essa afirmação, não se sustenta a inutilidade ou a incapacidade teórica e prática para entender as experiências brasileiras passadas e presentes. Quer-se, com isso, ressaltar apenas a adequação do exercício aproximativo no lugar da mera sobreposição entre elementos distintos.

Essa premissa elaborada conceitualmente consiste na afirmação de que a dynamis, a physis ou a phrónesis atenienses, por exemplo, têm pouco a dizer sobre as experiências brasileiras com a ideia de democracia. Contudo, trata-se de conceitos-chave para entender aquela sociedade antiga. De igual maneira, as experiências inglesas e da Europa continental registradas a partir do início do século XVI ou a experiência revolucionária 
das 13 colônias britânicas fornecem um repertório insuficiente para compreensão do fenômeno brasileiro.

Para imprimir maior concretude a esse argumento, basta recordar as elevadas expectativas atribuídas às revoluções ditas burguesas - iniciando pela Revolução Gloriosa, passando pela independência dos Estados Unidos da América até alcançar seu ápice com a Revolução Francesa - com a hipotética superação de um Ancien Régime baseado na força (física ou das armas) por um crescente Estado de direito (rule of law).

Écerto, porém, quando da formação do Estado brasileiro, que não restou configurado o surgimento de um terceiro Estado, tal qual descrito por Sieyès (2002). Isso não significa que o percurso brasileiro tenha se desenvolvido às margens dessas e de outras reflexões seminais ou até mesmo que a teoria do poder constituinte originário, fundada na titularidade da soberania do Estado nacional, não tenha desempenhado papel relevante para a formação do pensamento político brasileiro. Trata-se de contribuições necessárias, porém, insuficientes.

Compreende-se, então, que, por mais que tenha ocorrido o movimento federalista, originado nos Estados Unidos sob a forma centrípeta, isto é, a formação de uma federação pela reunião das ex-colônias, essa teoria não explica suficientemente a formação do Estado nacional brasileiro. Por outros caminhos, adotou a forma federada no sentido inverso, ou seja, os entes federados surgiram pelo desmembramento do Estado unitário ou centralizado: conhecido como federalismo centrífugo.

Nesse bojo, está inserida parcela expressiva do conteúdo das teorias contratualistas e liberais como forma de pactuação e de ordenação da sociedade civil. Em termos de abstração teórica, a crença da "razão autoesclarecida" (Aufklärung) apoiada no pensamento político coincide com a história da modernidade ocidental, contudo, o material fático insiste em embaralhar os limites estabelecidos entre a razão e a desrazão.

Os pensamentos primeiros e prevalentes no lado ocidental do mundo seriam, então, formas de representação cultural que fornecem uma compreensão localizada no tempo e no espaço. Reabre-se, portanto, a controversa questão do "universal” que ostenta a contradição no próprio termo: trata-se em um só tempo de algo uno e aplicável a todas as coisas. De outra sorte, com base numa pretensão mais modesta, seriam apenas considerações mínimas de um arranjo social entre tantos outros possíveis.

Há uma série de problemas acarretados pela hipótese de representar as realidades sociais e os pensamentos de maneira unívoca, sobretudo quando condicionados pelas perspectivas hegemônicas. Embora seja necessário conhecer os pensamentos político 
e filosóficos clássicos, é igualmente preciso ir além deles. A proposta consiste em interpretá-los na medida de suas contribuições e limitações. Ponto nodal a ser debatido nos próximos tópicos consiste na versatilidade e nas consequências da utilização do autoritarismo na orientação da ação política brasileira.

\section{O "autoritarismo instrumental" e o surgimento do "povo-massa" nas instituições políticas brasileiras}

Se a vanguarda dos pensamentos políticos europeu ou estadunidense não contempla integralmente as particularidades das instituições políticas brasileiras, sugere-se buscar em outras fontes para enviar às raízes do problema analisado, quer dizer, construir uma explicação minimamente razoável. Para tanto, os séculos iniciais do Brasil Império fornecem algumas pistas para mapear o fenômeno identificado.

Parece adequado interrogar alguns aspectos relacionados à formação do Estado nacional brasileiro, à constituição do povo e à organização social e política. A formação nacional supostamente se inicia com a colonização portuguesa, que corresponde a um tipo específico de colonialismo responsável pelo extermínio dos indígenas, pela escravidão de pessoas negras, pelos latifúndios (produtivos ou improdutivos), pelo analfabetismo, entre outros fatores. Contudo, atribuiu-se a "grande simplicidade da nossa estrutura social; pela ausência de antagonismo de classes; pela feição acentuadamente patriarcal da nossa sociedade" (VIANNA, 2004, p. 38) para explicar esse complexo fenômeno.

A questão racial emerge com centralidade na formação da sociedade brasileira. Em maior ou menor grau presente na caracterização dos tipos sociais do nordestino, do sulista e das populações meridionais (Rio de Janeiro, São Paulo e Minas Gerais), essa última responsável pela formação do "homem urbano"(VIANNA, 2005, p. 81). O "matuto acanhado" do meio rural e o "mestiço esperto" do meio urbano eram figuras que precisavam ser combatidas pelo processo de "embranquecimento" da população brasileira.

Revelam os traços da "consciência social” ou da "psicologia política” (VIANNA, 2005, p. 228) de um estrato social indefinido, marcado pela ausência de povo. O cidadão somente emerge do povo, mas aquele estaria prejudicado desde o início, visto que no Brasil o "homem do povo, o plebeu, o peão, o campônio não possui essa confiança interior e profunda", problemática maior reside no fato de não possuir "terras, nem 
escravos, nem capangas, nem fortuna, nem prestígio, sente-se aqui, praticamente, fora da lei. Nada o ampara. Nenhuma instituição, nem nas leis, nem na sociedade, nem na família, existe para a sua defesa” (VIANNA, 2005, p. 226).

No final das contas, o conjunto dessas reflexões servem para sustentar a inviabilidade das condições básicas da democracia, logo, “o autoritarismo é um instrumento transitório a que cumpre recorrer a fim de instituir no país uma sociedade diferenciada” (VIANNA, 2005, p. 35). A questão central é assim essencializada: se "Sempre vivemos dentro de um ambiente de semi-autoritarismos difusos” (VIANNA, 2005, p. 376), então o "homem do povo" é aquele que procura um chefe (VIANNA, 2005, p. 227).

$\mathrm{O}$ autoritarismo consagra, portanto, um certo agir estratégico que o torna instrumento para o alcance de determinados fins políticos, isto é, uma face que serve a diversas senhoras e senhores para atender a distintas finalidades. Estratégia que não respeita nem forma nem substância, parece apenas obedecer à finalidade de conquistar e manter-se no exercício do poder estatal. Com algumas peculiaridades, trata-se de um conceito aproximado de "zona de autarquia", porque, em ambos os casos, tem-se a "criação de espaços de decisão livres do controle da sociedade civil” (RODRIGUEZ, 2018, p. 105).

Francisco José de Oliveira Vianna, católico, sociólogo e jurista, foi ao mesmo tempo uma figura relevante e reacionária. Com proeminência na formação do pensamento político do período temporalmente localizado entre a transição da Primeira República e a ditadura do Estado novo. De perfil positivista e organicista, desde a transição do Império para a República, sustentava não existir "nenhuma aspiração definitivamente cristalizada na consciência das massas”(VIANNA, 2004, p. 92).

Por certo, não há um único Oliveira Vianna, existem pelo menos quatro modelos interpretativos demarcados (1) pelo autoritarismo instrumental, (2) pelo agrarismo ou ruralismo, (3) pelo iberismo e (4) pela ideologia de Estado. A interpretação de seus pensamentos varia desde o autêntico intérprete da história brasileira até o conservador e racista (SILVA, 2015). Em Instituições políticas brasileiras, apresenta uma explicação teórica bastante peculiar que encontra dificuldades de sustentação e recebe a classificação de "realismo reacionário" (VIEIRA, 2018, p. 94).

O caráter autoritário de sua teoria fundamenta a inviabilidade do regime democrático para o povo brasileiro, mas aposta na inserção de certos elementos democráticos por intermédio das ações estatais, especialmente do Judiciário. Nesse cenário, não há outra dimensão senão o Estado obstar a consecução de interesses privatistas, e disso 
decorre, em parte, seus posicionamentos iliberais; na melhor das hipóteses, o Brasil integra o grupo das "democracias de opinião infusa, inorganica [sic], inarticulada” (VIANNA, 1939, p. XV).

As causas de um “sistema político vertical e autoritário”(LAMOUNIER, 2009,p. 57) não são passíveis de interpretações atemporais ou descontextualizadas. Num horizonte autoritário, há interregnos temporais que não se amoldam a essas explicações; em certo sentido, esse diagnóstico datado explica parcela das fragilidades que as ideias de democracia e de participação social encontram no cenário brasileiro.

Fragilidade não significa inação ou impossibilidade de alteração de determinado estado de coisas, menos ainda naturalizar ou tornar imanentes determinadas ideias. Trata-se, de fato, de uma série de práticas reiteradas ao longo do tempo, o que torna difícil o desvencilhamento de seu legado autoritário. Antes pelo contrário, indica que, apesar das dificuldades enfrentadas, existe espaço para estabelecer disputas sobre a definição dos rumos da coisa pública; apesar das adversidades passadas e presentes; onde há opressão, certamente existem resistências.

O autoritarismo político adquire importância histórica quando se constitui como um dos instrumentos que cumprem recorrer a fim de instituir no país uma sociedade diferenciada, capaz de suportar as instituições políticas (VIANNA, 1999, p. 27). Quando presente nas mais variadas formas de relações, passa a formar, conformar e deformar as práticas institucionais e sociais na tarefa de regulação da vida em sociedade.

Designa, portanto, um conjunto objetivo de fatos, signos ou objetos que encadeados num sistema de representação simbólica e concreta se correlacionam a ideias, sentimentos, crenças e atos correspondentes (VIANNA, 1999, p. 94). Há também um elemento de preservação ou de conservação dessas bases autoritárias, “presente nas instituições do antigo Estado-Império ou de base aristocrática” (VIANNA, 1999, p. 125), que se conservam ignorando o atual status democrático. Esse ponto será recuperado no próximo tópico.

Vê-se que sua principal finalidade era assegurar um suposto "direito de imunidade" herdado de Portugal (VIANNA, 1999, p. 214). Nesse ponto de vista, o exercício arbitrário da autoridade precisou replicar o padrão europeu hegemônico que atravessou a formação dos clãs familiares e todas as relações políticas e sociais que daí decorrem, o chamado "complexo do feudo" (VIANNA, 1999), relações baseadas na propriedade privada de amplas extensões rurais determinadas e desenvolvidas de forma pouco ou nada republicana. 
Além disso, os traços de parentalidade e a religião católica forneceram contribuições para a “instituição do 'compadrio', donde saiu o tipo social do 'padrinho': - padrinho de casamento, padrinho de crisma, padrinho de batismo" (VIANA, 1999, p. 243). Nesse primeiro momento, as preocupações estavam centradas no fortalecimento e na perpetuação desses laços, poucos eram os laços que se estabeleciam em torno dos ideais democráticos.

Nessa análise, não há como sonegar a constatação desses fatos históricos e sociais para a formação do Estado nacional brasileiro. Progressivamente, surge o interesse político eleitoral como fator de aglutinação social e, pouco a pouco, o ideal de democracia representativa passa a ser configurado como um espectro ou uma miragem que igualmente reproduzia as assimétricas relações de poder presentes numa sociedade desigualmente organizada.

As figuras políticas do "senhor de engenho" e do “coronel” são representativas para ilustrar a capacidade de recriar formas autoritárias herdadas de um passado recente. Dentro desse contexto, surge espaço propício para a formação do "partido do coronel” (VIANNA, 1999, p. 266) derivado do coronelismo (ALMEIDA e FALEIROS, 2020; LAMOUNIER, 2009; SCHWARTZMAN, 2007 etc.). O autoritarismo prossegue com distintos graus no seu conteúdo e forma, pois as oligarquias rurais não se glutinaram para concretizar ideais democráticos, ao contrário, buscavam a instalação no poder político e a perpetuação de seus privilégios.

Consequentemente, surgem dois eixos para a compreensão do fenômeno político das instituições brasileiras: o "clã eleitoral” e o "povo-massa” (VIANNA, 1999). Diante da suposta ausência do povo brasileiro, o governo dos “melhores” é uma realidade a ser forjada por um longo percurso histórico eleitoral talhado em processos fraudulentos que reúnem condições para o surgimento de "eleitores fósforos”, de "capangas eleitorais" e das “eleições a bico de pena” (CARVALHO, 2002). Uma vez compreendidas as raízes dessa questão os comportamentos dos agentes envolvidos não deveriam surpreender.

Em certa medida, as instituições assumem a representação e as contradições da sociedade heterogênea e desigualmente estruturada. Por isso, os clãs e partidos não diferem substancialmente uns dos outros (VIANNA, 1999, p. 294) e remetem a uma das características que ainda prevalecem na política brasileira: a "carência de motivações coletivas”(VIANNA, 1999, p. 306). De mão de obra a eleitores não demorou muito para que ocorresse a apropriação performativa da ideia de democracia representativa que 
se satisfaz apenas com o voto popular. Eis o máximo de que o povo brasileiro poderia participar.

Povo seria apenas "uma aparência que se dissipa, quando vista de perto pela lente da realidade”(VIANNA, 1999, p. 373). Forçoso entender que o “povo-massa” não passa de uma figura retórica, ou seja, serve como material linguístico para argumentar meramente de modo persuasivo e sem correspondência com a experiência prática. Inexpressivo como categoria política justamente porque nunca teve participação, nem direta, nem de direito, no governo(VIANNA, 1999, p. 149).

O diagnóstico realizado pelo autor é preciso, já suas conclusões revelaram-se equivocadas. Em termos de sentimento nacional, segundo afirma, persiste a inferioridade do brasileiro em comparação ao alemão, ao inglês ou ao japonês. Além disso, entende que as oligarquias esclarecidas seriam então, realmente, a expressão da única forma de democracia possível no Brasil(VIANNA, 1999, p. 479).

Tais considerações precisam ser vistas, no mínimo, sob desconfiança. Porém, são aptas para retratar algumas das forças pouco democráticas bastante permeáveis no tecido social brasileiro, enquanto categoria heterogênea abstrata. Portanto, o autoritarismo brasileiro não possui um traço congênito e insuperável da “identidade nacional”, mas é certamente um dicionário poderoso(SCHWARTZMAN, 2007, p. 32) para compreender a gramática institucional e social. Não há como cerrar os olhos diante de uma tradição nacional que reproduz modelos assimétricos de relações de poder e de dominação.

Esses elementos formam o quadro de uma resposta teórica para a questão da persistência do autoritarismo que sugere ir além da "consciência do momento presente" (ADORNO; HORKHEIMER, 1985, p. 11). Cabe questionar se apontam para a continuidade histórica das práticas autoritárias ou, pelo acesso a outras fontes, seria possível chegar a conclusões diversas. Basicamente, essa é a tarefa que se pretende desenvolver no quarto tópico deste artigo.

\section{Persistências autoritárias versus cultura democrática}

As análises desenvolvidas no tópico anterior não levaram em consideração as alterações normativas, institucionais e sociais resultantes da promulgação da Constituição da República de 1988, pois o recorte temporal realizado por Vianna (1999) abrange os períodos da Constituição Política do Império do Brazil de 1824 até a elaboração da 
Constituição dos Estados Unidos do Brasil de 1946. De lá para cá, muitas situações foram modificadas e outras tantas, consolidadas.

Tais reflexões contribuem para o reforço metodológico da pesquisa, diante do desafio colocado pelo tratamento de diferentes obras analisadas ao longo do artigo. Ultrapassados mais de 31 anos de vigência da atual Constituição da República, duas posições são passíveis de confirmação. A primeira delas diz respeito à alteração da prática institucional e social para além da gramática constitucional. A segunda consiste na identificação de dois movimentos contrários: um de persistência autoritária e o outro em direção à formação de uma "cultura democrática”.

Conforme visto no tópico anterior, as instituições estatais brasileiras são explicadas, em larga medida, pela formação histórica que o colonialismo extrativista português se desenvolveu, bem como nas propriedades privadas de extensas porções territoriais rurais ou nas concentrações das forças produtivas durante o capitalismo industrializado, também chamado de "modernização conservadora" (CARVALHO, 2002). Outra parte, que não é inteiramente explicada pelas relações materiais e econômicas, diz respeito ao desenvolvimento das relações políticas no tempo e no espaço.

Nesse campo, as inserções são também assimétricas. De acordo com Deleuze (1992, p. 119-120), “as relações de força não se reduzem à violência, mas constituem ações sobre ações, ou seja, atos tais como 'incitar, induzir, desviar, facilitar ou dificultar, ampliar ou limitar, tornar mais ou menos provável'”. Aqui, ocorre o deslocamento para as experiências brasileiras.

A experiência histórica, de maneira geral, permite sustentar que se trata de um gatilho para duas situações distintas: a liberdade e o autoritarismo. Pela racionalização da atividade política, firmou-se um "pacto de poder" entre o Estado e a sociedade civil, consubstanciado num documento solene, escrito, que modernamente denomina-se constituição política (BUZANELLO, 1997, p. 30).

Uma das chaves de compreensão para o autoritarismo é a concentração do exercício do poder com o esvaziamento dos outros agentes e instituições, uma centralidade quase sempre exercida de maneira autoritária. A percepção de continuidade ou de progressão temporal dessas ideias encontrou apoio em expoentes do pensamento jurídico e Francisco Campos seria um exemplo icônico do autoritarismo aplicado no campo do conhecimento jurídico.

Desenha-se esse quadro com mais alguns exemplos. Até mesmo as constituições podem ser desvirtuadas por práticas autoritárias omissivas ou comissivas. No Brasil, o 
direito ao voto feminino, nas eleições nacionais, somente alcançou lastro constitucional com a Constituição de 1934. Os analfabetos também só puderam votar em 1985 a partir da Emenda Constitucional n. 25, que alterou a Constituição de 1967. Antes disso, pessoas do sexo feminino ou analfabetas sequer poderiam compor o conjunto do "povo-massa”.

O sistema de representação política em 1988 enveredou pelo multipartidarismo, contudo, ao que tudo indica, atualmente parece fazer mais parte do problema do que da solução. Segundo o Tribunal Superior Eleitoral, contabiliza-se em 33 o número de partidos políticos registrados (BRASIL, 2020), nem por isso, a crise do modelo representativo deixa de existir. Guardadas as devidas proporções, fenômeno semelhante foi identificado na "universalização" do voto popular, pois o "exercício do voto não garante a existência de governos atentos aos problemas básicos da população” (CARVALHO, 2002, p. 8).

Todavia, os votos capacitários simbolizam o projeto político e social que se desenhou durante bastante tempo no Brasil. No pensamento autoritário, interessa apenas valores como a unidade, a identidade e a homogeneidade (BARBOSA, 2018, p. 24), diversidade e pluralidade não apenas precisam ser evitadas, como também precisam ser combatidas.

Cabe acrescentar algumas peculiaridades do período ditatorial brasileiro. Durante a ditadura civil militar, 17 atos institucionais foram editados suspendendo a vigência da Constituição e dos direitos e das garantias fundamentais, dos direitos civis e políticos, ora em parte, ora por completo, contudo sem retirar a titularidade da soberania popular. Mesmo nos períodos de excepcionalidade, o "povo-massa” foi combinado com o autoproclamado "movimento revolucionário”, isto é, com o golpe civil militar.

Seja como for, os regimes autoritários se prestam a imunizar o poder político e o poder econômico da influência subversiva da sociedade civil organizada (RODRIGUEZ, 2018, p. 103). Precisamente nesse ponto, é necessário recuperar o tema das participações sociais como proposta teórica e empírica para a construção progressiva daquilo que se chama de cultura democrática.

As participações sociais assumem, nesse contexto de aplicação, a materialidade do projeto de democracia a partir e para além do voto popular. Entendida como potência em ato, participar deixa de ser um privilégio concedido a poucas pessoas e passa a ser manifestação, ainda que no plano simbólico, as ideias que alimentam a democracia e que paulatinamente são colocadas em movimento. 
O “buscar novas armas”, sobre o qual falava Deleuze (1992, p. 220), pode ser transposto para auxiliar no processo de repensar os paradoxos da participação social no contexto brasileiro - desenvolver um esforço contraintuitivo para conceber nas entrelinhas aquilo que não se deixa traduzir pelo corriqueiro. Apesar do ranço autoritário, existem espaços para as manifestações democráticas efêmeras e pontuais.

Ignorar as perspectivas de que tanto o histórico quanto a tradição brasileira depõem contrariamente às narrativas democráticas é discordar da ideia de persistência ou de continuidade do "autoritarismo instrumental". O futuro passa a ser entendido como uma trilha de possibilidades que permite tanto se limitar a repetir o passado quanto a reescrever e alterar os rumos da história até então conhecida. Essa primeira opção endossa o coro daquelas e daqueles que enxergam o "espírito nacional" como rarefeito e carente de densidade (VIANNA, 1999, p. 329).

Retoma-se o foco sobre a Constituição que ostenta a pretensão de disciplinar as discordâncias sociais históricas. Nesse sentido, o documento jurídico, político e social passa a ser entendido como um dos instrumentos potencialmente capazes para intermediar as disputas entre os movimentos de inspiração democrática, que buscam transformar realidades autoritárias e injustas e outros que atuam para manter esferas de arbítrios e hierarquias sociais (VIEIRA, 2018, p. 86).

Ocorrerão avanços democráticos significativos quando a tarefa constitucional de tentativa de refrear os ímpetos autoritários estatais e sociais se tornar exitosa ou majoritária. No entanto, tem-se presente o risco de romancear ou inflacionar as narrativas históricas. Constituições positivadas, por si sós, são incapazes de evitar a irrupção do autoritarismo, como também podem ser abertamente utilizadas por regimes autoritários (BARBOSA, 2018, p. 18). Sem dúvida, ocorre uma variedade de significações atribuíveis aos substantivos direito, política e autoritário.

Entretanto, contrariando a moda brasileira, a atual Constituição de 1988 foi elaborada e promulgada mediante procedimentos democráticos conduzidos por uma assembleia nacional constituinte eleita e com legitimidade popular. Contou também com a apresentação de emendas populares, com a realização de audiências públicas, com diversas comissões temática e subcomissões, com caravanas que percorreram o país inteiro, entre outras formas de participação social.

Isso indica a "pavimentação do caminho" para a construção da cultura democrática brasileira. O que se experienciou não foi apenas a mudança da gramática constitucional, mas também o prelúdio de outras práticas institucional e social, que de agora 
em diante se desenvolve (ou deveria desenvolver-se) com participação social ampliada. Num caminho em curso.

A agenda comum propositiva foi tratada pela assembleia nacional constituinte como uma questão pública, resultado de um movimento histórico: a "mobilização popular para exercer influência sobre os parlamentares era uma prática que havia adquirido certo grau de maturidade e articulação nos movimentos organizados” (BARBOSA, 2018, p. 230).

Muito embora a "batalha interpretativa em torno da memória” atribuída ao processo constituinte seja “inconclusa” (BARBOSA, 2018, p. 244), a estrutura decisória passou por sensíveis modificações. Por mais que se distancie do ponto de vista defendido, não há como ignorar cerca de 9 milhões de pessoas que passaram pela constituinte entre os meses de março e novembro de 1987, as quase 200 audiências públicas realizadas, as 12 mil propostas encaminhadas e perto de 7 mil emendas e anteprojetos (VIEIRA, 2018, p. 116).

A Constituição enquanto objeto de disputas interpretativas autointeressadas e não como um local seguro de garantias privilegia a formação de um status cívico e também acentua as disparidades entre as relações de força desigualmente distribuídas na sociedade. Pontuar o efetivo impacto do papel desempenhado pelas participações sociais na organização política exige mudanças estruturais capazes de transcender o mero “verniz democrático” (MENEZES, 2019, p. 255). Isso, no entanto, constitui desafio para pesquisas futuras.

\section{Considerações finais}

Em vista da problematização exposta e dos materiais consultados, foi possível confirmar a hipótese inicialmente apresentada e considerar as implicações advindas de um desenho institucional brasileiro realizado com base numa tradição de pouca aderência democrática. Isso, por sua vez, provoca dificuldades normativas e operativas para que as participações sociais se realizem numa dimensão ampliada.

A conclusão central alcançada pelo empreendimento da pesquisa teórica realizada consiste em compreender que tomar contato com os clássicos ou com os pensamentos políticos consagrados no lado ocidental do mundo não fornece os traços distintivos para compreender a experiência brasileira, que possui fragilidades e paradoxos singulares. De outra sorte, sugere-se estabelecer rigorosos e constantes diálogos. 
Entender pela manutenção ou pela rejeição de um projeto autocrático de poder depende das interpretações daquilo que tradicionalmente se entende por liberdade e por servidão. Subordinados ao campo da experiência ou prática social, esses elementos variam no tempo e no espaço. Ainda que imersas num processo de "redemocratização", tanto a democracia quanto as participações sociais, apesar dos significativos avanços, ainda não se incorporaram completamente nas práticas institucionais brasileiras.

Abrem-se, por fim, novas frentes de trabalho consistentes em identificar as atrizes e os atores sociais, ou o conjunto, que mobilizam essas participações sociais e, na sequência, mensurar os possíveis impactos provocados na experiência democrática brasileira. Todavia, conforme já se disse, são desafios para futuras pesquisas.

\section{REFERÊNCIAS}

ADORNO, T. W.; HORKHEIMER, M. A dialética do esclarecimento: fragmentos filosóficos. Tradução Guido Antonio de Almeida. Rio de Janeiro: Jorge Zahar, 1985.

ALMEIDA, S.; FALEIROS, J. L. O coronelismo de Victor Nunes Leal e a modernização conservadora: colocações iniciais. Revista de Direito, Viçosa, v. 12, n. 1, p. 1-26, 2020.

BARBOSA, L. A. de A. História constitucional brasileira: mudança constitucional, autoritarismo e democracia no Brasil pós-1964. 3. reimpr. Brasília: Edições Câmara, 2018.

BERMAN, H. J. Direito e revolução: a formação da tradição jurídica ocidental. Tradução Eduardo Takemi Kataoka. São Leopoldo: Unisinos, 2006. (Coleção Díke).

BOBBIO, N. Teoria geral da política: a filosofia política e as lições dos clássicos. Tradução Daniela Beccaccia Versiane. 10. ed. Rio de Janeiro: Elsevier, 2000.

BRASIL. Partidos políticos registrados no TSE. Brasília, 20 jun. 2020. Disponível em: http://www.tse. jus.br/partidos. Acesso em: 20 jun. 2020.

BUZANELLO, J. C. Controle de constitucionalidade: a Constituição como estatuto jurídico do político. Revista de Informação Legislativa, Brasília, v. 34, n. 136, p. 29-36, out./dez. 1997.

CARVALHO, J. M. de. Cidadania no Brasil: o longo caminho. 3. ed. Rio de Janeiro: Civilização Brasileira, 2002.

CARVALHO, J. M. de. Os três povos da República. Revista USP, São Paulo, n. 59, p. 96-115, set./nov. 2003.

DELEUZE, G. Conversações. Tradução Peter Pál Pelbarte. São Paulo: Editora 34, 1992. (Coleção Trans). GOMES, D. F. L. Brasil, 2020: tentativa de diagnóstico. In: GOMES, D.; CATTONI DE OLIVEIRA, M. 30 anos, e agora? Direito e política nos horizontes da República de 1988 - Em homenagem a Juarez Guimarães. Belo Horizonte: Conhecimento, 2020, p. 1-32. No prelo. 
HAN, B.-C. Psicopolítica: o neoliberalismo e as novas técnicas de poder. Tradução Maurício Liesen. Veneza: Âyiné, 2018.

IANNI, O. Enigmas da modernidade-mundo. 3. ed. Rio de Janeiro: Civilização Brasileira, 2003.

LA BOÉTIE, E. de. Discours de la servitude volontaire. Paris: Payot, 1976.

LAMOUNIER, B. Bases do autoritarismo revisitado: diálogo com Simon Schwartzman sobre o futuro da democracia Brasileira. In: SCHWARTZMAN, F. F. et al. (org.). O sociólogo e as políticas públicas: ensaios em homenagem a Simon Schwartzman. Rio de Janeiro: Fundação Getúlio Vargas, 2009. p. 53-66.

MENEZES, D. F. N. Olegado autoritário presente na Constituição Federal de 1988. Cadernos do Programa de Pós-Graduação em Direito/UFRGS, Porto Alegre, v. XIV, n. 1, p. 254-274, 2019.

ORWELL, G. 1984. Tradução Heloisa Jahn e Alexandre Hubner. São Paulo: Companhia das Letras, 2019.

RODRIGUEZ, J. R. Um novo ciclo autoritário: para uma democracia multinormativa. In: ENGELMANN, W.; ROCHA, L. S.; STRECK, L. L. (org.). Constituição, sistemas sociais e hermenêutica: anuário do Programa de Pós-Graduação em Direito da Unisinos. São Leopoldo: Karywa, 2018. p. 100-126.

SCHWARTZMAN, S. Bases do autoritarismo brasileiro. 4. ed. Rio de Janeiro: Publit Soluções, 2007.

SIEYĖS, E. J. Qu'est-ce que le Tiers Etat?. Paris: Du Boucher, 2002.

SILVA, F. X. da. As quatro faces de Oliveira Vianna. Política e Sociedade, Florianópolis, v. 14, n. 30, p. 132-159, maio/ago. 2015.

VIANNA, O. O idealismo da Constituição. 2. ed. Rio de Janeiro: Companhia Editora Nacional, 1939.

VIANNA, O. Instituições políticas brasileiras. Brasília: Senado Federal, 1999. (Biblioteca básica brasileira).

VIANNA, O. O ocaso do império. Brasília: Senado Federal, 2004. (Edições do Senado Federal, v. 26).

VIANNA, O. Populações meridionais do Brasil. Brasília: Senado Federal, 2005. (Edições do Senado Federal, v. 27).

VIEIRA, O. V. A batalha dos poderes: da transição democrática ao mal-estar constitucional. São Paulo: Companhia das Letras, 2018. 